This item was submitted to Loughborough's Research Repository by the author.

Items in Figshare are protected by copyright, with all rights reserved, unless otherwise indicated.

\title{
Bed disturbance via foraging fish increases bedload transport during subsequent high flows and is controlled by fish size and species
}

PLEASE CITE THE PUBLISHED VERSION

http://dx.doi.org/10.1016/j.geomorph.2015.09.021

\section{PUBLISHER}

(C) Elsevier

VERSION

AM (Accepted Manuscript)

\section{PUBLISHER STATEMENT}

This work is made available according to the conditions of the Creative Commons Attribution-NonCommercialNoDerivatives 4.0 International (CC BY-NC-ND 4.0) licence. Full details of this licence are available at: https://creativecommons.org/licenses/by-nc-nd/4.0/

\section{LICENCE}

CC BY-NC-ND 4.0

\section{REPOSITORY RECORD}

Pledger, Andrew G., Stephen P. Rice, and Jonathan Millett. 2019. "Bed Disturbance via Foraging Fish Increases Bedload Transport During Subsequent High Flows and Is Controlled by Fish Size and Species". figshare. https://hdl.handle.net/2134/19327. 
Bed disturbance via foraging fish increases bedload transport during subsequent high flows and is controlled by fish size and species

$$
\text { A.G. Pledger }{ }^{a_{\star}} \text {, S.P. Rice }{ }^{a} \text {, and J. Millett }{ }^{a}
$$

${ }^{a}$ Loughborough University, Leicestershire, UK, LE11 3TU

*Corresponding author email: andrew.pledger@reaseheath.ac.uk Present address of corresponding author: Reaseheath College, Nantwich, Cheshire, CW5 6DF 


\section{Abstract}

Benthic foraging by fish can modify the nature and rates of fine sediment accrual and the structure and topography of coarse-grained fluvial substrates, with the potential to alter bed material characteristics, particle entrainment thresholds, and bedload transport fluxes. However, knowledge of what controls the nature, extent, and intensity of benthic foraging and the consequent influence of these controls on geomorphic impact remains rudimentary. An ex-situ experiment utilising Barbel Barbus barbus and Chub Leuciscus cephalus extended previous work by considering the role of fish size and species as controls of sediment disturbance by foraging and the implications for bed material characteristics and bedload transport. In a laboratory flume, changes in bed microtopography and structure were measured when a water-worked bed of 5.6-22.6 mm gravels was exposed to four size classes of Barbel (4-5", 5-6", 6-8", 8-10" in length) and a single size class of Chub (8-10"). In line with other studies that have investigated animal size as a control of zoogeomorphic agency, increasing the size of Barbel had a significant effect on measured disturbance and transport metrics. Specifically, the area of disturbed substrate, foraging depth, and the fish's impact on microtopographic roughness and imbrication all increased as a function of fish size. In a comparison of the foraging effects of like-sized Barbel and Chub, 8-10" in length, Barbel foraged a larger area of the test bed and had a greater impact on microtopographic roughness and sediment structure. Relative to water-worked beds that were not foraged, bed conditioning by both species was associated with increased bedload transport during the subsequent application of high flows. However, the bedload flux after foraging by Barbel, which is a specialist benthivore, was 150\% higher than that following foraging by Chub, which feed opportunistically from the bed, and the total transported mass of sediment was $98 \%$ greater. An interesting implication of these results, given the abundance and widespread distribution of foraging fish, is that numerous fish species belonging to a variety of functional groups may be acting as zoogeomorphic agents in rivers, directly affecting bed material conditions and sediment transport fluxes in proportion to their body size and feeding traits.

Keywords: ecosystem engineering; Barbel; Chub; imbrication; bedload transport; zoogeomorphology 



\section{Introduction}

Our understanding is growing of how animals, plants, fungi, and microorganisms can affect the nature and rates of geomorphological processes (Viles, 1988; Butler, 1995; Naiman et al., 2000; Reinhardt et al., 2010) and in doing so, act as ecosystem engineers (Jones et al., 1994). With regard to fluvial systems, reviews by Statzner (2011), Rice et al. (2012), and Albertson and Allen (2014) highlight the geomorphic capabilities of fish and macroinvertebrate fauna; but the number of studies is small and limited to a few species and impact mechanisms. The majority of research has focused on bed bioturbation during spawning by Salmonids (Field-Dodgson, 1987; Kondolf et al., 1993; Montgomery et al., 1996; Hassan et al., 2008), bed and bank bioturbation by crayfish (Statzner et al., 2003a; Zhang et al., 2004; Johnson et al., 2011; Harvey et al., 2014; Rice et al., 2014) and substrate consolidation through silk secretion by hydropsychid caddisflies (Cardinale et al., 2004; Johnson et al., 2009; Albertson et al., 2014).

Rice et al. (2012, their Figure 19.6) highlight a range of additional mechanisms by which fish and invertebrates might affect bed material conditions and thence sediment transport in gravel-bed rivers. Amongst these, foraging by fish is a potentially widespread and effective zoogeomorphic activity, but very little work has explored this possibility. Some work has considered the impact of detrivorous, tropical fish on fine sediment accrual within lotic systems (Flecker, 1996; 1997; Flecker and Taylor, 2004), finding that foraging reduced sediment accrual (Bowen et al., 1984; Lopez and Levington, 1987; Vari, 1989; Flecker, 1992) and that the effect increased with species density (Bowen, 1983; Goulding et al.,1988). European Cyprinid species reduce fine sediment accrual within lotic and lentic environments. Specifically, Carp Cyprinus carpio have been found to resuspend fine sediment when foraging for food (Breukelaar et al., 1994; Parkos et al., 2003; Chumchal et al., 2005; Miller and Crowl, 2006; Roozen et al., 2007; Matsuzaki et al., 2009); and other benthic feeders such as Bream Abramis brama, Tench Tinca tinca, and Ruffe Gymnocephalus cernus modify fine sediment accrual rates and increase turbidity (Persson and Svensson, 2006) whilst foraging.

Three further studies have considered the zoogeomorphic impact of benthic foraging fish on coarse fluvial sediments. First, Statzner et al. (2003b) used ex-situ experiments in small (0.2-m-wide) outdoor channels to investigate the impact of 
juvenile Barbel Barbus barbus on unstructured, fine gravel beds. They measured a decrease in the critical shear stress (for gravel entrainment) of $\sim 45 \%$ as the number of fish that were allowed to forage the bed was increased from zero to eight (Statzner et al., 2003b). Significant increases in mean bed elevation and the authors' observation that the fish heaped gravel into piles led them to suggest that increased mobility was caused by the fish loosening the bed and increasing particle elevations. Second, Statzner and Sagnes (2008) investigated the joint effects of Barbel, Gudgeon (Gobio gobio), and the spiny-cheek Crayfish (Orconectes limosus) and found that their net joint effects on sediment mobility were generally less than the sum of the impacts of the individual species. These findings emphasise the role of biotic factors in controlling geomorphic impact. Third, Pledger et al. (2014) found that foraging juvenile Barbel modified water-worked surface gravels, undoing stable imbricate structures and increasing microtopographic roughness. These changes coincided with an average increase in initial bedload flux and overall sediment yield of $60 \%$ and $82 \%$, respectively, under entrainment flows. Collectively, results from these three studies suggest that benthic foraging can have a significant impact on fluvial sediment characteristics, thereby influencing sediment transport processes under laboratory conditions and justifying the need for further study to gain greater understanding of benthic foraging as a geomorphic activity.

Understanding the geomorphological importance of animals requires an understanding of how abiotic and biotic factors mediate zoogeomorphic impact (e.g., Figure 7b in Johnson et al., 2011). With regard to foraging, Statzner et al. (2003b) and Statzner and Sagnes (2008) have shown that biotic controls (specifically between-species interactions and shoaling, respectively) are relevant in this regard. Many other potentially important factors (biotic or abiotic), however, could influence foraging behaviour and therefore geomorphic impact in rivers. Temperature (Lemons and Crawshaw, 1985; Nerici et al., 2012), predator presence (Fraser and Huntingford, 1986; Ibrahim and Huntingford, 1989), and shoal feeding (Pitcher and Parrish, 1993), for example, have been shown to significantly influence the nature, duration, and frequency of feeding; but their effect on foraging behaviour, and thence geomorphic impact, is poorly understood.

An additional, potentially important, factor is body size because large animals could have a greater impact and modify sediment composition differently relative to smaller 
specimens. Indeed, Moore (2006) proposed that the most effective ecosystem engineers are likely to be those that have greater body mass. This is supported by studies showing that (i) the geomorphic effects of spawning fish increase with the size of individuals (cf. Burner, 1951) and (ii) physiological and anatomical differences associated with fish size could explain differences in their geomorphic impact when spawning (cf. Barber et al., 2001). Another, potentially important, factor that might control geomorphic impact whilst foraging is feeding habit, which varies between species and reflects a multitude of biological, physiological, and behavioural differences and adaptations.

The effects of fish size and species on bed disturbance by benthic foraging fish and the consequent impacts on bedload transport under subsequent high flows are therefore the focus of this paper. An ex-situ flume experiment was undertaken with two components. To investigate the role of fish size, the foraging effects of four size classes of a single species, Barbel (4-5", 5-6", 6-8" and 8-10" in length), on bed material disturbance and subsequent transport were compared (component 1). To investigate the role of species, the foraging effects of like-sized Barbel and Chub, 810 " in length, on bed material disturbance and subsequent transport were compared (component 2). Barbel and Chub were chosen for comparison in component 2 because they are two common, benthic-feeding fish that occupy similar habitats but have different physiologies and specific feeding habits, as illustrated by Pledger et al. (2014; their Table IV), and therefore potentially different zoogeomorphic capabilities and impacts. Expectations are that larger fish will have a greater impact and that Barbel being a benthic foraging specialist will have a greater geomorphic impact than Chub, a renowned opportunistic forager. The specific aim of this experiment was to test the following hypotheses:

Hypotheses pertaining to component 1:

(1) Foraging Barbel alter the arrangement and organisation of gravel-bed substrates as measured by imbrication and microtopography, and this effect increases with fish size.

(2) Structural and compositional changes to the bed as a function of foraging by Barbel significantly increase (a) grain entrainment, (b) bedload flux, and (c) 
total transported mass during subsequent high flows. The magnitude of this effect increases with fish size.

Hypotheses pertaining to component 2:

(3) Foraging Barbel and Chub alter the arrangement and organisation of gravelbed substrates as measured by imbrication and microtopography. Because of their preference for benthic foraging and unique physiology, the impact of Barbel is greater than that of Chub.

(4) Structural and compositional changes to the bed as a function of foraging by Barbel and Chub significantly increase (a) grain entrainment, (b) bedload flux and (c) total transported mass during subsequent high flows. Because of their preference for benthic foraging and unique physiology, the impact of Barbel is greater than that of Chub.

\section{Methodology}

\subsection{Fish husbandry}

The experiment utilised four size classes of Barbel and a single size class of Chub (Table 1) that were hatchery-raised and born of captivity-reared broodstock at Hampshire Carp Hatcheries, UK. Fish lengths in meters are provided in Table 1 for the reader but are presented hereafter in imperial units to be consistent with those supplied by the hatchery.

The protocol pertaining to fish husbandry was consistent with that described in Pledger et al. (2014, p. 1501), with two modifications. First, water in two 1000-I holding tanks was cooled and maintained at a constant temperature of $16.70^{\circ} \mathrm{C} \pm$ 0.003 ( \pm 1 standard deviation). Second, during experiments and the intervening periods between experimental runs, a Teco TR120 water cooler was permanently installed to cool the water in the flume storage tanks. Given that fish metabolism and the amount a fish is required to eat to sustain body mass is sensitive to temperature, limiting the effect of temperature during the experiment was appropriate. 
Water quality parameters were monitored throughout each experimental period to ensure environmental conditions remained within fish tolerances, using a YSI 6600 V2 probe ( $\mathrm{pH}$, dissolved oxygen, conductivity) and a Tinytag PLUS 2 temperature sensor: temperature $=14.68 \pm 0.14^{\circ} \mathrm{C} ; \mathrm{pH}=8.39 \pm 0.026$, conductivity $=397.20 \pm$ $2.11 \mu \mathrm{S} / \mathrm{l}$, dissolved oxygen $=10.39 \pm 0.076 \mathrm{mg} / \mathrm{l}$, dissolved oxygen $=102.46 \pm$ $0.66 \%$ (mean \pm 1 standard deviation).

\subsection{Flume setup}

Experiments were conducted in a glass-sided, tilting flume, $0.3 \mathrm{~m}$ wide and with a 10-m-long working section. The flume setup (Fig. 1) was almost identical to that used and described by Pledger et al. (2014), where additional details can be found. In brief, a central part of the working section (5.75 m long) was fenced off to contain fish and partitioned into two subsections: an observation area filled with a mobile sediment mixture and a downstream acclimatisation area, separated from the observation area by a removable fence (Fig. 1A). Adjacent to this fence, at the downstream end of the observation area, was a bedload slot sampler $(0.275 \times 0.125$ $x 0.1 \mathrm{~m}$ ) that could be covered when transport measurements were not being made. In the centre of the observation area was a smaller patch, the test bed, that was used to evaluate changes in microtopography using repeat laser scanning (Fig. 1B). The sediment mixture in the observation area was slightly coarser than the mixture used in Pledger et al. (2014) and consisted of a log-normal grain-size distribution of 5.6-22.6 mm gravels $\left(D_{5}=6.1 \mathrm{~mm}, D_{50}=10.0 \mathrm{~mm}, D_{95}=19.3 \mathrm{~mm}\right)$. Marine gravels

were used that were predominantly bladed (Sneed and Folk, 1958) and well rounded (Krumbein, 1941).

\subsection{Experimental procedure}

In 72 separate flume runs, bedload transport was measured during the application of an identical high flow following conditioning of the bed in two distinct ways: in 12 replicates the bed was screeded flat to produce a level sediment surface and then water-worked to produce a stable natural texture and fabric similar to that expected 
in the field (no foraging control); and in 60 runs, fish from each of five groups (four Barbel size classes and the single Chub size class) were allowed to forage across the bed after water-working and prior to application of the high entrainment flow (foraging treatment). Twelve fish were obtained in each size class, but individuals grew during the experimental period, so replicate numbers (i.e., number of runs) varied from 4 to 16 between the five with-Barbel and with-Chub foraging treatments (Table 1). Comparisons between no foraging controls and foraging treatments isolated the impact of feeding on a stable, natural, water-worked substrate.

In an additional set of 12 replicate screeded runs, the bed was screeded flat but not water-worked or exposed to fish prior to application of the same entrainment flow. These runs provided an estimate of maximum transport rate for the unstable sediment mixture. Knowing this is useful in order to demonstrate the important impact of water-working on bed stability, which has not been a feature of previous experiments of this kind.

In the no foraging control and foraging treatment runs, there were three sequential elements (Fig. 2): phase 1, in which a moderate flow water-worked the gravel bed; phase 2, in which a low flow was imposed and the bed was either left untouched (control runs) or foraged by fish (treatment runs); and phase 3, in which a high flow capable of entraining sediment and generating bedload transport was applied. Phases 1 and 3 were identical in all runs, but the procedure in phase 2 differed between control and treatment runs as explained below. In the screeded set, phase 1 was omitted and phase 2 was treated as in the control runs (Fig. 2B).

Hydraulic conditions during the three phases are described in Table 2. Hydraulic measurements were obtained from velocity profiles collected with either a Nixon Streamflo velocity meter V1.3 with a high-speed probe, averaging over 60 seconds or a Vectrino ADV (20Hz sample rate; $60-$ second sample period). Two instruments were necessary to manage the large variation in flow velocity between phases, and direct comparisons confirmed consistency in their time-averaged measurements (Pledger et al., 2014). Velocity profiles were collected above the centre of the test bed at 2.5-mm intervals through the bottom $20 \%$ of the flow and at increasing vertical increments above and typically consisted of 22 to 26 points. Twenty-five profiles were collected during the 84 runs to check consistency between runs. These 
profiles were used to estimate near-bed shear stresses $\left(\tau_{0}\right)$ using the law of the wall (Biron et al., 1998; Robert, 2003), corrected for sidewall drag using Williams' (1970) empirical approach. Dimensionless Shields' parameters $(\theta)$ were calculated using the median grain size $D_{50}=10 \mathrm{~mm}$.

\subsubsection{Phase 1: Moderate water-working flow}

During phase 1, a flow was generated with bed shear stress slightly above the critical threshold required for particle mobility (Shields number $=0.020$; Table 2 ). The unstructured, screeded bed was water-worked for one hour during which time sediment that collected in the bedload slot sampler (Fig. 1B) was reintroduced upstream of the observation area to encourage the development of a natural, dynamic bed structure. At the end of this phase, in all runs, the test section was then laser scanned to obtain bed elevation data for characterising microtopography and bed structure (Fig. 2).

\subsubsection{Phase 2: Low flow, with or without fish foraging}

During this phase, different procedures were adopted in the control and treatment runs. In the 60 treatment runs involving fish, the protocol was similar to that described by Pledger et al. (2014). In brief, the observation area was seeded with larval Chironomidae (hereafter bloodworm) at the average prey density $\left(3548 \mathrm{~m}^{-2}\right.$ ) measured in a Barbel-rich reach of the River Idle, UK. The flume was slowly filled, which washed the bloodworms into interstitial gaps. Flow conditions were designed to ensure a low-stress environment for all size classes and both fish species and were insufficient to mobilise bed sediments (Table 2). A single fish was then placed in the acclimatisation area for one hour, after which the temporary fence was removed, allowing fish access to the observation area. Access began at sunset and lasted four hours because in rivers, Barbel are crepuscular foragers (Baras, 1995; Lucas and Batley, 1996). At the end of this period, the fish was carefully corralled back into the acclimatisation area and removed from the flume. Each treatment run used a different individual fish. Given that runs were performed at dusk and into the hours of darkness, video recording was precluded by ambient light conditions. 
However, visual observations were made throughout each run to ensure the behaviours of foraging fish were consistent with those observed within the River Idle and described by Pledger et al. (2014) in that (i) fish foraged facing upstream into the flow and (ii) the specific feeding mechanisms adopted by Barbel and Chub in the flume were similar to those utilised by fish in the field.

The flow condition during phase 2 was insufficient to affect bed sediments with a Shields number of 0.00042 , well below the threshold for motion or entrainment. No evidence of particle movements, vibration, or rearrangement was observed at this flow, confirming that the flow had no impact on bed condition. Therefore, during the 12 no foraging control runs, it was unnecessary to expose the bed to the entire fivehour duration used in the runs with fish. However, it was important to run the flow for some period so that the draining and refilling operations between phases 1-2 and 2-3 in the treatment runs were duplicated in the control runs too, in case these operations had any impact on bed sediment characteristics. Therefore, the flume was carefully filled in the usual way and the phase 2 flow was run for 10 minutes, after which the flume pump rate was gradually reduced until discharge reached zero and the flume was allowed to drain slowly to preserve bed structures (Table 2).

At the end of phase 2 in foraging treatment and no foraging control runs, the test section was again laser scanned to obtain bed elevation data for characterising microtopography and bed structure (Fig. 2). Collection of scans during control runs provided data for establishing minimum discernible differences in surface elevation data, required for DEM analysis (see section 3.1).

\subsubsection{Phase 3: Entrainment flow}

In all runs, flume slope, pump speed, and tailgate height were then altered and the flume was filled carefully for the final time. In this phase, the flow had the highest bed shear stress, which exceeded the critical level for particle mobility (Shields number = 0.025; Table 2) such that there was moderate entrainment. Phase 3 lasted for one hour (Fig. 2). 


\subsection{Measurements of bed surface microtopography and bedload characteristics}

\subsubsection{Bed elevations and bed structures}

Surface elevations across the test bed were measured using a Konica-Minolta non contact 3D Digitiser Vivid 910, mounted above the flume. The scanning procedure and data processing necessary to derive DEMs of each surface was standard and is described in detail in Pledger et al. (2014). The DEMs had an $x-y$ spacing of $1 \mathrm{~mm}$ and were used to address hypotheses (1) and (3).

\subsubsection{Bedload flux}

During the entrainment phase, bedload measurements were made every five minutes by emptying the pit trap and weighing the trapped sediment. Sediment flux and unit cumulative mass for the one-hour period were obtained from the bedload measurements. Trap width $(0.275 \mathrm{~m})$ rather than flume width $(0.3 \mathrm{~m})$ was used to calculate per unit width values. Bedload measurements contributed to the assessment of hypotheses (2) and (4).

\section{Data analysis}

3.1. The effect of foraging on bed surface microtopography and surface structures Topographic changes due to foraging were quantified by creating DEMs of Difference (DoDs) from DEMs of the test bed before and after exposure to fish. Minimum discernible difference DoDs were calculated from DEMs obtained in the 12 pairs of scans collected at the end of phases 1 and 2 during no foraging control runs (Fig. 2). In each case, DEMs collected at the end of phase 1 were subtracted from those obtained at the end of phase 2, providing a measure of the influence of draining and filling operations on bed surface topography, and of the errors associated with the capture, rectification, and interpolation of DEMs from laser scanner point clouds. During controls, the maximum calculated elevation difference was $0.6 \mathrm{~mm}$ and an error factor of $\pm 1 \mathrm{~mm}$ was therefore applied as a liberal estimate of the minimum discernible difference in surface elevation. Topographic differences exceeding the $\pm 1 \mathrm{~mm}$ threshold were considered to be the result of fish foraging. 
Data derived from the DoDs were used during three analyses: first, an analysis was performed of the total area of the test bed disturbed (i.e., area of DoD where value exceeded $\pm 1 \mathrm{~mm}$ ) to assess how this varied with fish size (component 1 ) and species (component 2). The four Barbel size classes and the single Chub size class were combined as a single factor, with five treatments (four size classes of Barbel and one size class of Chub) in a univariate general linear model (GLM). This is equivalent to a one-way ANOVA but allows analysis of the uneven numbers of replicates in our study. The GLM was used to assess whether fish size class (comparing the four size classes of Barbel) and species (comparing 8-10" Barbel and Chub), had significant effects on disturbance area (\%). Within the model, the treatment (fish size class and species) was specified as a fixed effect. If the GLM reported a significant effect, differences between treatments were tested using a protected Fisher's least significant difference (Fisher's LSD hereafter) post-hoc test.

Second, an analysis identified how maximum foraged depth (i.e., the highest negative value on the DoD) varied with fish size (component 1) and species (component 2). The same analyses described above (GLM + Fisher's LSD post-hoc tests) were applied to data pertaining to maximum depth rather than total area foraged.

Third, an analysis investigated the nature of foraging within disturbed areas for each species and size class of fish. Foraging disturbance was partitioned into four discrete categories: surface rearrangement (positive and negative) was defined as a topographic change greater than the minimum discernible difference $( \pm 1 \mathrm{~mm})$ but less than $\pm 10 \mathrm{~mm}$, the median diameter of the bed material. Topographic changes $>10 \mathrm{~mm}$ may reflect displacement of individual grains rather than their in-situ rearrangement and were categorised as surface gain if the elevation difference was positive or as surface retreat if the difference was negative. Simple summary statistics were used to analyse these data.

For each scanned test bed, several surface properties were extracted and compared between experimental groups. Standard deviations of surface elevations $\left(\sigma_{z}\right)$ were used as a surrogate for microtopographic roughness (Aberle and Smart, 2003). In addition, the degree of particle structuring or imbrication in the stream wise direction was quantified and compared using Smart et al.'s (2004) inclination index $I_{l}$. Data 
were tested for normality using Shapiro-Wilkes tests, and paired $t$-tests were used to compare pre- and post-foraging mean values for all size classes and species of fish. To supplement these data, differences between pre- and post-foraging values were also calculated $\left(\Delta \sigma_{z}\right.$ and $\left.\Delta I_{l}\right)$ for each size class. Data were analysed using the same approach described above (GLM + Fisher's LSD post-hoc tests) such that two discrete sets of analyses were performed: one set on microtopographic roughness data $\left(\Delta \sigma_{z}\right)$ and the other on inclination index data $\left(\Delta I_{l}\right)$. These were important tests to identify whether fish size (component 1) and species (component 2) had significant effects on the magnitude of change to microtopographic roughness and sediment structure.

\subsection{The effect of foraging on entrainment and bedload}

Direct comparisons were made between screeded and no foraging and between no foraging and foraging runs to quantify the effects of water-working and feeding, respectively, on sediment transport. Of particular interest was an assessment of the impact of foraging using the first measurement of average bedload flux, between $t=$ 0 and $t=300$ seconds, during phase 3 . This was an important test of fish impact because bed restructuring and a consequent decline in transport was expected (and observed) as phase 3 progressed. The impact of fish on the unit cumulative mass deposited in the bedload trap was also assessed. Once again, GLM + Fisher's LSD post-hoc tests were applied to these data to identify whether fish size (component 1 ) and feeding habit (component 2) had significant effects.

To determine the temporal persistence of any impact on sediment flux, the role of fish across the entire measurement time series (to $t=3600$ seconds) was tested using a Linear mixed model (LMM). Autocorrelation between time points was accounted for with a first-order autoregressive (AR(1) hereafter) covariance structure. A compound symmetry structure was also tested, but the model using an $A R(1)$ structure was more appropriate, as determined by Akaike's information criterion (AIC). Within the model, experimental runs were subjects and time was the repeated measure. Time and treatment (4-5", 5-6", 6-8", and 8-10" Barbel; 8-10" Chub; water-worked; screeded) were specified as fixed factors. All data analysis was carried out using IBM SPSS Statistics v21.0. 


\section{Results}

4.1. The effect of fish size and species on the spatial and vertical extent of bed disturbance

The total proportion of the test bed area disturbed by foraging fish, during the fourhour exposure period, varied between fish treatments (GLM; $F_{4,55}=37.08, P<$ 0.001 ; Fig. 3A). The percentage disturbed area (i.e., elevation change $> \pm 1 \mathrm{~mm}$ ) increased with Barbel size (hypothesis 1) from 26\% to 69\% for 4-5" and 8-10" fish, respectively. Only the two smallest classes showed no statistically significant difference in their impact (Fig. 3A: Fisher's LSD; $P=0.34$ ). In relation to species effects, 8-10" Chub disturbed $32 \%$ of the test bed area, significantly less than the same size Barbel and, indeed, smaller 6-8" Barbel (Fig. 3A: Fisher's LSD; $P<0.001$ ) (hypothesis 3). Within the disturbed portion of the test bed, the majority of the disturbance fell within the surface rearrangement categories (Fig. 3B): 97\%, 97\%, 94\%, and 92\% for 4-5", 5-6", 6-8", and 8-10" size classes of Barbel, respectively, and $97 \%$ for the $8-10 "$ size class of Chub.

On average, the maximum depth that fish foraged varied between fish treatments (GLM; $F_{4,55}=5.43, P=0.001$; Fig. 4). Maximum foraging depths increased with fish size when comparing the four size classes of Barbel (hypothesis 1). Specifically, significant differences were observed between the largest size class of Barbel (810") and the three smallest: 4-5" (Fisher's LSD; $P=0.001$ ), 5-6" (Fisher's LSD; $P=$ 0.001), and 6-8" (Fisher's LSD; $P=0.01$ ). In relation to species effects, no significant difference was found in maximum disturbance depth when comparing results from 810" Chub and Barbel (Fisher's LSD; $P=0.50$ ) (hypothesis 3 ).

4.2. The effect of fish size and species on gravel-bed microtopography and imbrication

Measurements of $\sigma_{z}$ before and after foraging showed significant increases in bed microtopography after the test section was exposed to 5-6", 6-8", and 8-10" Barbel and 8-10" Chub (paired t-tests; $\alpha=0.05$; Table 3). The change in $\sigma_{z}$ following foraging by $4-5$ " Barbel was not statistically significant (paired $t$-tests; $\alpha=0.05$; Table 
3). Water-worked gravels that were not exposed to fish, but which were subject to the same flume refilling and draw down operations between scans, did not show a significant change in $\sigma_{z}$ (paired $t$-test: $t_{11}=0.60, P=0.56$ ), with a small average difference, $\Delta \sigma_{z}$ of 0.023 , equivalent to $38 \%$ of the average change recorded for the smallest Barbel treatment.

Differences in elevation standard deviation $\Delta \sigma_{z}$ before and after foraging were significantly different between fish treatments (GLM: $\left.F_{4,55}=28.81, P<0.001\right)$ with larger increases in $\Delta \sigma_{z}$ associated with larger fish (Fig. 5A). Between species, 8-10" Chub generated smaller increases in $\Delta \sigma_{z}$ than 8-10" Barbel, and this difference was statistically significant (Fig. 5A; Fisher's LSD; $P<0.001$ ) (hypothesis 3).

Foraging also affected the structure of the gravel bed. The initial water-working created imbricated surface texture with an asymmetric distribution of inclinations consistent with values observed in natural, gravel-bed rivers $\left(0.03<I_{l}<0.18\right.$; Millane et al., 2006). In water-worked control runs without fish, but subject to the same flume refilling and draw down operations between scans, changes in $I_{l}$ between scans were extremely small and not significant (paired $t$-test: $t_{11}=0.09, P=$ 0.92). For the fish treatment runs, significant reductions in $I_{l}$ were measured after foraging by all sizes of Barbel and 8-10" Chub (Table 3).

The magnitude of the change in imbrication before and after foraging, $\Delta I_{l}$ varied significantly between fish treatments (GLM: $F_{4}=8.15, P<0.001$; Fig. 5B). The largest size class of Barbel (8-10") was associated with a significantly larger reduction in imbrication than the three smaller sizes, which all recorded a similar reduction in $I_{l}$ (Fig. 5B) (hypothesis 1). Between species, Chub produced a reduction in inclination comparable with the 4-5", 5-6", and 6-8" Barbel, which was significantly less than the 8-10" Barbel (Fig. 5B; Fisher's LSD; $P<0.001$ ) (hypothesis 3).

\subsection{The effect of foraging on bedload transport during a subsequent high flow}

Over the hour-long entrainment period, mean bedload transport rates declined during all runs. During fish runs when 4-5", 5-6", 6-8", and 8-10" Barbel had been present in the flume, values declined from 0.00076 to $0.00028,0.00076$ to 0.00073 , 0.0015 to 0.00068 , and 0.0026 to $0.00081 \mathrm{~kg} \mathrm{~m}^{-1} \mathrm{~s}^{-1}$, respectively (Fig. 6). For 8-10" 
Chub, average sediment flux declined from 0.001 to $0.00054 \mathrm{~kg} \mathrm{~m}^{-1} \mathrm{~s}^{-1}$. During water-worked and screeded control runs, flux values declined from 0.00059 to 0.00032 and from 0.0043 to $0.00068 \mathrm{~kg} \mathrm{~m}^{-1} \mathrm{~s}^{-1}$, respectively. This general pattern of declining bedload flux was expected as less stable particles were quickly entrained, and the bed became increasingly structured under the entrainment flow. The foraged beds adjusted toward the same transport condition as the control beds because the flow and bed sediment mixtures were identical in both cases. Of much greater interest is the difference in transport rate and cumulative transported mass between the foraged and control beds, which demonstrates the impact of bed preconditioning by foraging fish on the impact of a high flow.

Considering the full-time series out to the final 5-minute measurement between 3300 and 3600 seconds (Fig. 6), the impact of foraging was persistent: there were significant effects of time (LMM: $\left.F_{11}=15.36, P=<0.001\right)$, treatment (LMM: $F_{6}=$ 15.86, $P<0.001)$, and a significant interaction between the two (LMM: $F_{66}=3.50, P$ $<0.001$ ). The relatively gross measurements of flux (integrated over 5-minute intervals) almost certainly lead to an underestimation of the fish effect. Extrapolation of the data toward time $=0$ suggests a much greater initial difference in bedload transport rates between fish treatments (with-Barbel and with-Chub) and waterworked control runs, such that these results are conservative.

Initial bedload flux measurements made between 0 and 300 seconds varied significantly between treatments (GLM: $F_{6,77}=34.56, P<0.001$; Fig. 7). As expected, water-working significantly reduced sediment flux during the first 300 seconds of entrainment relative to screeded runs (Fig. 7; Fisher's LSD; $P<0.001$ ), which emphasises the effect of water-working and bed structure on sediment mobility. Relative to the transport rate from water-worked beds, sediment fluxes were higher after foraging. However, these differences were significant only for the treatments involving 6-8" and 8-10" Barbel (Fisher's LSD; $P=0.005$ and $<0.001$, respectively). Sediment flux increased with Barbel size such that there were significant increases in the 0-300 second transport rate between the two smallest size classes and the 6-8" class and, in turn, between the 6-8" and 8-10" classes (Fisher's LSD; $1.8 \times 10^{-9} \leq P \leq 0.01$ ) (hypothesis 2). Species also had a clear effect (Fig. 7) in that the 0-300 second sediment flux from substrates disturbed by Chub was not significantly different from the water-worked control runs and was 
significantly lower than the flux from beds disturbed by 6-8" and 8-10" Barbel (Fisher's LSD; $P=0.005$ and $P<0.001$, respectively) (hypothesis 4).

Over the one-hour entrainment phase, the cumulative mass of transported bedload varied significantly between treatments (GLM: $F_{6,77}=14.94, P=<0.001$; Fig. 8). As expected, water-working significantly reduced total transported mass relative to screeded beds (Fisher's LSD; $P<0.001 ;$ Fig. 8). Some fish treatments were also significant with increases in transported mass after exposure to 6-8" and 8-10" Barbel that were significantly greater than the cumulative mass measured in waterworked runs (Fisher's LSD; $P=0.009$ and <0.001, respectively; Fig. 8). The amount of transported sediment was significantly greater from beds foraged by 6-8" Barbel than from beds foraged by the two smallest classes and was greater still from beds foraged by the largest 8-10" fish (hypothesis 2). Notably, there was no significant difference in the cumulative mass moved off beds disturbed by 8-10" Barbel and screeded beds (Fisher's LSD; $P=0.16$ ). Species was also significant; beds disturbed by 8-10" Barbel yielded more sediment than those foraged by Chub of the same size (Fisher's LSD; $P<0.001$ ) (hypothesis 4).

\section{Discussion}

Foraging Barbel and Chub modified the microtopography and structure of waterworked gravel substrates, increasing microtopographic roughness while reducing the degree of imbrication imparted to the river bed by water-working flows. As hypothesised, these impacts were greater for larger fish (hypothesis 1) and for Barbel relative to Chub (hypothesis 3). Significant impacts were observed between both species and across all size classes, with the exception of 4-5" Barbel. The majority of microtopographic alterations fell within the \pm 10 - to \pm 1 -mm disturbance categories, with only a relatively small proportion of all elevation changes exceeding the diameter of the $D_{50}(10 \mathrm{~mm})$. This suggests that feeding Barbel and Chub, irrespective of size, predominantly foraged within the surface layer and modified microtopography and structure by moving individual grains and altering their attitude and position rather than by digging pits or creating mounds of multiple grains.

The disturbances to water-worked bed materials caused by foraging were associated with measureable differences in sediment transport when entrainment flows were 
subsequently applied to the experimental beds (hypotheses 2 and 4). Bedload flux during the first 5 minutes of the entrainment flow was significantly higher $(\alpha=0.05)$ by $161 \%$ and $340 \%$ for beds that had been foraged by $6-8$ " and $8-10$ " Barbel, respectively, relative to fluxes from water-worked control runs. Over the same period, smaller Barbel (4-5" and 5-6") and 8-10" Chub were also associated with measured increases in bedload of $30 \%, 30 \%$, and $76 \%$, relative to water-worked runs, but these increases were not statistically significant $(\alpha=0.05)$. Increases in sediment flux as a function of foraging also manifested as significant increases in total transported bedload for 6-8" and 8-10" Barbel. The cumulative impact of smaller size classes of Barbel and of Chub on total transported mass were not statistically different to the yield from water-worked control surfaces that had not been exposed to fish.

\subsection{Fish size and species as controls of a fishes' zoogeomorphic impact}

\subsubsection{Fish size effects}

Feeding primarily disturbed the surface layer. For Barbel, however, there was a noticeable increase in the proportion of the scanned surface, which fell into the elevation gain and retreat categories in experiments using larger specimens (Fig. 3B). This implies that larger Barbel consistently foraged at greater depths within the substrate, which is confirmed by the clear relationship between fish size and maximum foraging depth (hypothesis 1). The total proportion of the scanned surface that was disturbed also increased with fish size (hypothesis 1; Fig. 3A).

It is possible that these and the other size effects measured in this study reflect physiological and anatomical differences between size classes. For example, it is reasonable to propose that Barbel size is a proxy for stomach capacity such that larger fish were relatively unconstrained by stomach size and could therefore feed for longer and disturb a greater surface area (Fig. 3A). Similarly, it is likely that increases in size and strength are responsible for observed increases in foraged depth (Fig. 4) and area (Fig. 3A) because large fish found it easier to forage deeper and move more bed material relative to smaller conspecifics. Qualitative observations of foraging behaviour support these hypotheses in that larger Barbel were observed displacing grains by distances that exceeded their diameter, while 
subtle adjustments to the orientations of grains were predominately associated with smaller size classes of fish. In turn, these size-related differences in the spatial extent and the mechanical rigour of foraging activity can explain the fish size impacts on topographic roughness (Fig. 5A) and sediment structure (Fig. 5B).

Results from this experiment therefore extend and support those from previous studies that have shown size to be an important control of a fishes' zoogeomorphic impact (e.g., Burner, 1951; Barber et al., 2001). To extend laboratory findings into field situations, future research could investigate the nature of relations between animal size and geomorphic impact and whether ex-situ relations can usefully predict in-situ impacts. In this context, allometric relations between fish size and the spatial and vertical extents of foraging have been developed for the Barbel data reported here (Fig. 9). These are nondimensionalised by the bed material grain size and mass to facilitate comparisons across alternative animal-substrate interactions.

\subsubsection{Species effects}

Species was found to be an important control of foraging extent (hypothesis 3): when comparing 8-10" Barbel and Chub, Barbel consistently disturbed a larger surface area. The geomorphic impacts of Barbel <8" in length were found to be similar or greater than those of the larger 8-10" Chub. For example: 6-8" Barbel disturbed more substrate while foraging, and the area disturbed by 4-6" and 5-6" Barbel was not significantly different from 8-10" Chub; in relation to their impacts on grain inclination and microtopographic roughness, Chub had a similar or significantly lower impact than smaller 4-5", 5-6", and 6-8" Barbel. These results imply that Barbel were more effective than Chub at benthic foraging, from a geomorphological perspective, such that smaller specimens of Barbel had similar or greater geomorphic impacts than larger Chub.

There are four possible reasons for the reduced substrate impact of Chub relative to Barbel. First, between-species anatomical differences, e.g., stomach size, might have meant that Barbel were required to feed more. Second, Barbel might have maintained a higher metabolic rate than Chub, meaning they were required to feed and forage more to sustain or increase body mass. Third, Chub might have been physically less effective at disturbing the river bed whilst foraging by displaying 
different foraging behaviours to and maintaining a lower size-to-strength ratio than Barbel. Fourth, Chub have developed a number of adaptive traits and feeding behaviours that mean they are not reliant on the bed for food (Pledger et al., 2014). Differences in adaptive traits between the species could mean that Chub utilised bed sediments less than Barbel in their search for food during the experiment, which might explain relative differences in their geomorphic impacts. Although there is no explicit evidence to prove or disprove these different hypotheses, qualitative observations suggest that Barbel were more effective foragers in terms of their zoogeomorphic capabilities due to their unique physiology and preference for specialised benthic feeding behaviours, e.g., push + gulping, in accordance with Pledger et al.'s (2014) classification scheme.

\subsubsection{Changes in bed sediment characteristics caused changes in bedload flux}

Two arguments strongly suggest that the measured changes in bed sediment characteristics explain the observed increase in bedload flux during fish runs. First, the degree of stabilising particle imbrication was reduced by foraging fish, and the magnitude of that impact varied as a function of fish size and species type (hypotheses 1 and 3). Imbrication is regarded as a stabilising phenomenon because individual particles are in attitudes that minimise drag and because grain-on-grain interaction demands that individual grains have to be pried loose from the constraints of neighbouring particles (Komar and Li, 1986; Church et al., 1998; Church, 2010). During the experiment, feeding essentially undid water-worked imbricate structures, reducing the degree of inclination, with significant differences recorded before and after foraging for Chub and all but the smallest size class of Barbel (Table 3). Qualitative observations confirmed effective reversal of inclinations during runs using 5-6", 6-8", and 8-10" Barbel, as fish utilised the push + gulping behaviour so that after foraging, bed particles showed a propensity to dip downstream rather than upstream. However, this did not manifest as changes in the sign of inclination index values, turning mean positive to mean negative values, as observed by Pledger et al. (2014), probably because inclination indices were calculated for the entire test bed in this experiment but only for the disturbed portions of the test bed in the earlier work. Fish of both species predominantly foraged whilst facing upstream into the flow, which allowed them to easily penetrate the interstices between upstream dipping, 
imbricated grains to force them apart and rotate them into vertical positions or turn them through their pivot angles into obtuse positions. Increased total transported mass (hypothesis 2), particularly for the 6-8" and 8-10" size classes, suggest that this rendered particles relatively more mobile, probably by increasing the drag on them, by increasing their protrusion and by freeing them from the constraints of their neighbours. Interestingly, there was no significant difference between the total transported bedload in 8-10" Barbel and screeded runs (Fisher's LSD; $P=0.16$ ). This implies that fish disturbed bed sediment structures to such an extent that the gravel particles in foraged beds were as unstable and prone to movement as if deposited randomly, unaffected by any water-working.

Second, significant increases in the standard deviation of surface elevations after exposure to fish (significant for all size classes and species of fish with the exception of the 4-5" size class of Barbel), imply the production of a less-packed surface fabric, in which some grains became more exposed to the flow- for example, by displacement of neighbours or by direct elevation gain. It is reasonable to hypothesise that this increased the mobility of individual grains by increasing the drag upon them and by increasing protrusion. Modest increases in protrusion can be important because grain entrainment is sensitive to protrusion (Fenton and Abbott, 1977).

5.1.4. Implications of fish foraging behaviour for sediment transport in rivers: influence of biotic and abiotic factors

This experiment extends previous work on the zoogeomorphic effects of benthic foraging (Stazner et al., 2003b; Statzner and Sagnes, 2008; Pledger et al., 2014) by showing that fish size and species are important controls of bed conditioning by feeding and of subsequent bedload transport during high flows. Assuming that these ex-situ results have relevance in the field, then the implication is that benthic foraging has the potential to affect coarse sediment transport in streams and rivers, especially at places or times where feeding fish interact with and therefore destabilise waterworked bed materials.

Scaling up experimental results in time and space to natural situations in rivers is a key challenge in freshwater ecology (e.g., Peckarsky et al., 1997, Peckarsky, 1998), 
in fluvial geomorphology (e.g., Ashmore, 1982; Paola et al., 2009), and in ecogeomorphological studies (e.g., Rice et al., 2010; Johnson et al., 2011, their Figure 7b). However, it is reasonable to anticipate that what was observed in the flume is, at some level, representative of foraging effects in the field; and there are several good reasons to hypothesise that benthic feeding is a prolific and effective bed disturbance mechanism in rivers. First, in natural settings, the two species examined here and other benthic feeders grow large. For instance, adult Barbel in the UK can achieve weights of $9.3 \mathrm{~kg}, 664$ and 98 times heavier (respectively) than the smallest and largest size classes of the fish used in these experiments. If the size-dependent effects on disturbance extent and bedload transport continue to scale with fish size, it is reasonable to hypothesise that natural populations that include large adults can have a substantial impact on bed material condition. However, we must acknowledge that ontogenetic shifts in the feeding behaviour of Chub, whereby fish become increasingly piscivorous with age, might cause mature fish to disturb the bed less and have a smaller impact on bed material stability, relative to juvenile specimens. Equally, an increase in food requirements of mature relative to juvenile fish might have the opposite effect, with mature fish foraging the river bed more to sustain or increase body mass. Further work is therefore required to investigate bed utilisation whilst feeding and how this varies between species and as a function of fish size. Second, benthic foraging is a common feeding behaviour and the demonstration here that specialist (Barbel) and opportunistic (Chub) foragers can have a geomorphic impact implies that many species belonging to different functional groups are capable of acting as zoogeomorphic agents. Third, it is likely that foraging occurs where and whenever benthic feeding fish are present, albeit within seasonal constraints imposed by differences in food availability and metabolism, via water temperature. This suggests that foraging may have a persistent and spatially extensive impact on bed materials, perhaps extending the zoogeomorphic potential of fish across large portions of river networks and beyond the relatively more constrained impacts of lithophilic spawning (cf, Hassan et al., 2008).

It is also important to note that in natural settings there is a trade-off between the size and abundance of organisms in a population (White et al., 2007). For example, the majority of fish within healthy systems are small, with only a small proportion 
being large adults. Whilst the individual impact of larger fish may be greater, it is reasonable to assume that smaller fish might still have important impacts due to their abundance within natural systems.

In the absence of in-situ experiments and large-scale field observations, these ideas remain hypothetical but justify the continued investigation of foraging impacts. Laboratory experiments do not account for the numerous biotic and abiotic factors that might influence the location, frequency, and nature of foraging under natural conditions. For example, riverine fish have access to and gain sustenance from a wide variety of environments, and differences in habitat and thence food utilisation will likely occur as functions of fish size and type (e.g., for Barbel, cf. Bischoff and Freyhof, 1999). Therefore, it is reasonable to assume that the relationship between fish size, species, and geomorphic impact via foraging will be more complex than in experimental systems where hydrological, ecological, and geomorphological conditions are stringently controlled. A number of key issues, in addition to the need for work in natural settings, will therefore improve understanding of the foraging effect, including fuller understanding of how feeding behaviour and fish-sediment interactions vary with fish maturity across species and functional groups; the spatial and temporal footprint of benthic feeding across different species, sizes of fish, and functional groups; and the role of conspecific and interspecific interactions, including shoaling behaviour, in moderating fish-sediment interactions (cf. Statzner and Sagnes, 2008).

\section{Conclusion}

Foraging Barbel and Chub modified water-worked surface gravels, reducing the degree of imbrication and increasing microtopographic roughness. This conditioning increased bedload flux during a subsequent high flow, with transport rates up to $340 \%$ higher from beds that had been foraged compared with beds that had been water-worked but not exposed to fish. These findings support and extend the observations of Stazner et al. (2003b) and Statzner and Sagnes (2008) and the quantitative findings of Pledger et al. (2014) regarding the zoogeomorphic importance of benthic foraging. In particular, this work is novel in demonstrating that fish species and size are important controls of a fishes' foraging effect, with larger 
fish and the species that is a specialist benthic feeder (Barbel) having the greatest impacts. This result is consistent with other studies that have investigated the effects of organism size on geomorphology (e.g., spawning and nest-building behaviour cf. Burner, 1951; Kondolf et al., 1993; Barber et al., 2001). While it is not unexpected that Barbel are more effective geomorphic agents given their physiology and behavioural adaptations to foraging, it is notable that Chub also had an impact, despite being opportunistic rather than specialist benthic feeders. At river-scale, foraging specialists and foraging opportunists are abundant, often grow large, are widely distributed, and feed perennially, albeit at a rate that reflects seasonal variations in metabolism. It is therefore possible to hypothesise that benthic foraging is a powerful zoogeomorphic activity in natural settings, with the potential to affect river-bed stability and sediment transport across large portions of river networks.

\section{ACKNOWLEDGEMENTS}

The authors would like to thank Loughborough University and The Barbel Society for providing financial support; Matthew Johnson, Alan Henshaw, and lan Wellby for general help and advice; Stuart Ashby, Richard Hartland, and Barry Kenny for help with equipment; and Hampshire Carp Hatcheries for providing the Barbel and Chub. Four anonymous reviewers are also thanked for their positive, helpful, and constructive suggestions. 


\section{References}

Aberle J, Smart GM. 2003. The influence of roughness structure on flow resistance on steep slopes. Journal of Hydraulic Research 41: 259-269.

Albertson LK, Allen DC. 2014. Meta- analysis: abundance, behaviour and hydraulic energy shape biotic effects on sediment transport in streams. Ecology 96 (5): 13291339.

Albertson LK, Sklar LS, Pontau P, Dow M, Cardinale BJ. 2014. A mechanistic model linking insect (Hydropsychidae) silk nets to sediment motion in gravel-bedded streams. Journal of Geophysical Research 119 (9): 1833-1852.

Ashmore PE. 1982. Laboratory modelling of gravel, braided stream morphology. Earth Surface Processes and Landforms 7: 201-225.

Baras E. 1995. Seasonal activities of Barbus barbus: Effect of temperature on timebudgeting. Journal of Fish Biology 46: 806-818.Barber I, Nairn D, Huntingford FA. 2001. Nests as ornaments: revealing construction by male sticklebacks. Behavioural Ecology 12: 390-396.

Biron PM, Lane SM, Roy AG, Bradbrook KF, Richards K. 1998. Sensitivity of bed shear stress estimated from vertical velocity profiles: the problem of sampling resolution. Earth Surfaces Processes and Landforms 23 (2): 133-139.

Bischoff A and Freyhof J, 1999. Seasonal shifts in day-time resource use of $0+$ barbel, Barbus barbus. Environmental Biology of Fishes 56: 199-212.

Bowen SH. 1983. Detritivory in neotropical fish communities. Environmental Biology of Fishes 9: 137-144.

Bowen SH, Bonetto AA, Ahlgren MO. 1984. Microorganisms and detritus in the diet of a typical neotropical riverine detritivore, Prochilodus platensis (Pisces: Prochilododontidae). Limnology and Oceanography 29: 1120-1122.

Breukelaar AW, Lammens E, Breteler J, Tatrai I. 1994. Effects of benthivorous bream (Abramis brama) and carp (Cyprinus carpio) on sediment resuspension and concentrations of nutrients and chlorophyll-a. Freshwater Biology 32: 113-121.

Burner CJ. 1951. Characteristics of spawning nests of Columbia River salmon. Fisheries Bulletin 52: 97-110. 
Butler DR. 1995. Zoogeomorphology: animals as zoogeomorphic agents. Cambridge, UK: Cambridge University Press.

Cardinale BJ, Gelmann ER, Palmer MA. 2004. Net spinning caddisflies as stream ecosystem engineers: the influence of hydropsyche on benthic substrate stability. Functional Ecology 18: 381-387.

Chumchal MM, Nowlin WH, Drenner RW. 2005. Biomass-dependent effects of common carp on water quality in shallow ponds. Hydrobiologia 545: 271-177.

Church M, Hassan MA, Wolcott JF. 1998. Stabilizing self-organized structures in gravel-bed stream channels: Field and experimental observations. Water Resources Research 34: 3169-3180.

Church M. (2010) Gravel-bed rivers in Burt T, Allison R (Eds), Sediment Cascades: An Integrated Approach, 241-270. John Wiley and Sons, Chichester.

Field-Dodgson MS. 1987. The effect of salmon redd excavation on stream substrate and benthic community of two salmon spawning streams in Canterbury, New Zealand. Hydrobiologia 154: 3-11.

Flecker AS. 1992. Fish trophic guilds and the organization of a neotropical stream: weak direct versus strong indirect effects. Ecology 73: 927-940.

Flecker AS. 1996. Ecosystem engineering by a dominant detritivore in a diverse tropical stream. Ecology 77: 1845-1854.

Flecker AS. 1997. Habitat modification by tropical fishes: environmental heterogeneity and the variability of interaction strength. Journal of the north American Benthological Society 16: 286-295.

Flecker AS, Taylor BW. 2004. Tropical fishes as biological bulldozers: density effects on resource heterogeneity and species diversity. Ecology 85: 2267-2278.

Fraser DF, Huntingford FA. 1986. Feeding and avoiding predation hazard: the behavioural response of prey. Ethology 73: 56-68.

Goulding M, Carvalho ML, Ferreira FG. 1988. Rio Negro: rich life in poor water. SPB Academic, The Hague, the Netherlands. 
Harvey GL, Henshaw AJ, Moorhouse TP, Clifford NJ, Holah H, Grey J, Macdonald DW. 2014. Invasive crayfish as drivers of fine sediment dynamics in rivers: field and laboratory evidence. Earth Surface Processes and Landforms 39: 259-271.

Hassan MA, Gottesfeld AS, Montgomery DR, Tunnicliffe JF, Clarke GKC, Wynn G, Jones-Cox H, Poirier R, Maclsaac E, Herunter H and Macdonald SJ. 2008. Salmondriven bedload transport and bed morphology in mountain streams. Geophysical Research Letters 35: L0440 doi:10.1029/2007GL032997

Ibrahim AA, Huntingford FA. 1989. Laboratory and field studies of the effect of predation risk on foraging in three-spined sticklebacks (Gasterosteus aculeatus L.). Behaviour 109: 46-57.

Johnson MF, Reid I, Rice SP, Wood J. 2009. Stabilisation of fine gravels by netspinning caddisfly larvae. Earth Surface Processes and Landforms 34: 413-423.

Johnson MF, Rice SP, Reid I. 2011. Increase in coarse sediment transport associated with disturbance of gravel river beds by signal Crayfish (Pacifastacus leniusculus). Earth Surfaces Processes and landforms 36: 1680-1692.

Jones CG, Lawton JH, Shachak M. 1994. Organisms as ecosystem engineers. Oikos 69: 373-386.

Komar PD, Li Z. 1986. Pivoting angles of the selective entrainment of sediments by shape and size with application to gravel threshold. Sedimentology 33: 425-436.

Kondolf GM, Sale MJ, Wolman MG. 1993. Modification of fluvial gravel size by spawning salmonids. Water Resources Research 29: 2265-2274.

Krumbein WC. 1941. Measurement and geological significance of shape and roundness of sedimentary particles. Journal of Sedimentary Petrology 11: 64-72.

Lemons E, Crawshaw LI. 1985. Behavioral and metabolic adjustments to low temperatures in the Largemouth Bass (Micropterus salmoides). Physiological Zoology 58 (2): 175-180.

Lopez GR, Levington JS. 1987. Ecology of deposit-feeding animals in marine sediments. Quarterly Review of Biology 62: 235-259. 
Lucas MC, Batley E. 1996. Seasonal movements and behaviour of adult Barbel Barbus barbus, a riverine cyprinid fish: Implications for river management. Journal of Applied Ecology 33: 1345-1358.

Matsuzaki SS, Usio N, Takamura N, Washitani I. 2009. Contrasting impacts of invasive engineers on freshwater ecosystems: an experiment and meta-analysis. Oecologia 158: 673-686.

Millane RP, Weir MI, Smart GM. 2006. Automated Analysis of Imbrication and Flow Direction in Alluvial Sediments Using Laser-Scan Data. Journal of Sedimentary Research 76: 1049-1055.

Miller SA, Crowl TA. 2006. Effects of common carp (Cyprinus carpio L.) on macrophytes and invertebrate communities in a shallow lake. Freshwater Biology 51: 85-94.

Montgomery DR, Buffington JM, Peterson NP, Schuett-Hames D, Wuinn TP. 1996. Stream-bed scour, egg burial depths, and the influence of salmonid spawning on bed surface mobility and embryo survival. Canadian Journal of Fish and Aquatic Science 54: 1061-1070.

Moore JW. 2006. Animal ecosystem engineers in streams. Bioscience 56: 237-246.

Naiman RJ, Elliott SR, Hellfield JM, O'Keefe TC. 2000. Biophysical interactions and the structure and dynamics of riverine ecosystems: the importance of biotic feedbacks. Hydrobiologia 410: 79-86.

Nerici C, Merino G, Silva A. 2012. Effects of two temperatures on the oxygen consumption rates of Seriolella violacea (palm fish) juveniles under rearing conditions. Aquacultural Engineering 48: 40-46.

Paola C, Straub K, Mohrig D, Reinhardt L. 2009 The "unreasonable effectiveness" of stratigraphic and geomorphic experiments Earth-Science Reviews 97: 1-43.

Parkos JJ, Santucci VJ, Wahl DH. 2003. Effects of adult common carp (Cyprinus carpio) on multiple trophic levels in shallow mesocosms. Canadian Journal of Fisheries and Aquatic Science 60: 182-192. 
Peckarsky BL. 1998. "The dual role of experiments in complex and dynamic natural systems" in Resetarits WJ Jr. and Bernardo J (Eds)., Experimental Ecology: Issues and Perspectives, Oxford University Press, New York, pp. 311-423.

Peckarsky BL, Cooper SD, Mclntosh AR. 1997. Extrapolating from Individual Behavior to Populations and Communities in Streams. Journal of the North American Benthological Society, Vol. 16, No. 2, New Concepts in Stream Ecology: Proceedings of a Symposium, pp. 375-390.

Persson A, Svensson JM. 2006. Effects of benthivorous fish on biogeochemical processes in lake sediments. Freshwater Biology 51: 1298-1309.

Pitcher TJ, Parrish JK. 1993. Functions of shoaling behaviour in teleosts. In Behaviour of teleost fishes (second edition), Pitcher TJ (ed), Chapman and Hall, 2-6 Boundary Row, London, UK.

Pledger AG, Rice SP, Millett J. 2014. Reduced bed material stability and increased bedload transport caused by foraging fish: a flume study with juvenile Barbel (Barbus barbus). Earth Surface Processes and Landforms 39 (11): 1500-1513.

Reinhardt L, Jerolmack D, Cardinale BJ, Vanacker V, Wright J. 2010. Dynamic interactions of life and its landscape: feedbacks at the interface of geomorphology and ecology. Earth Surface Processes and Landforms 35: 78-101.

Rice SP, Lancaster J and Kemp P. 2010. "Experimentation at the interface of fluvial geomorphology, stream ecology and hydraulic engineering and the development of an effective, interdisciplinary river science", Earth Surface Processes and Landforms 35: 64-77.

Rice SP, Johnson MF and Reid I. 2012. "Animals and the Geomorphology of Gravelbed Rivers" in Church M, Biron P and Roy AG (Eds), Gravel-bed rivers: processes, tools, environments, 225-241. John Wiley and Sons, Chichester

Rice SP, Johnson MF, Extence C, Reeds J, Longstaff H. 2014. Diel patterns of suspended sediment flux and the zoogeomorphic agency of invasive crayfish. Cuadernos de Investigación Geográfica 40 (1): 7-27.

Robert, A. 2003. River Processes. An Introduction to Fluvial Dynamics. Arnold Publishers, London, UK, 214. 
Roozen F, Lurling M, Vlek H, Kraan E, Ibelings BW, Scheffer M. 2007. Resuspension of algal cells by benthivorous fish boosts phytoplankton biomass and alters community structure in shallow lakes. Freshwater Biology 52: 977-987.

Smart GM, Aberle J, Duncan M, Walsh J. 2004. Measurement and analysis of alluvial bed roughness. Journal of Hydraulic Research 42: 227-237.

Sneed ED, Folk RL. 1958. Pebbles in the lower Colorado River, Texas: a study in particle morphogenesis. Journal of Geology 66: 114-150.

Statzner B. 2011. Geomorphological implications of engineering bed sediments by lotic animals. Geomorphology 157: 49-65.

Statzner B, Sagnes P. 2008. Crayfish and fish as bioturbators of streambed sediments: assessing joint effects of species with different mechanistic abilities. Geomorphology 3: 267-287.

Statzner B, Peltret O, Tomanova S. 2003a. Crayfish as geomorphic agents and ecosystem engineers: effect of a biomass on base flow and flood-induced transport of gravel and sand in experimental streams. Freshwater Biology 48: 147-163.

Statzner B, Sagnes P, Champagne J-Y, Viboud S. 2003b.Contribution of benthic fish on the patch dynamics of gravel and sand transport in streams. Water Resources Research 39 (11): 1-17.

Vari RP. 1989. A phylogenetic study of the neotropical characiform family Curimatidae (Pisces: Ostariophysi). Smithsonian Contributions to Zoology, 471.

Viles HA. 1988. Introduction. IN Viles, H.A., ed., Biogeomorphology. Basil Blackwell, New York, 319-30.

Williams GP. 1970. Flume width and water depth effects in sediment-transport experiments: sediment transport in alluvial channels. Geological survey professional paper 562-H, United States Government Printing Office, Washington.

White EP, Ernest SKM, Kerkhoff AJ, Enquist BJ. 2007. Relationships between body size and abundance in ecology. Trends in Ecology and Evolution 22 (6): 323-330. 
Zhang Y, Richardson JS, Negishi JN. 2004. Detritus processing ecosystem engineerin and benthic diversity: a test for predator-omnivore interference. Journal of Animal Ecology 73: 3162-3173. 

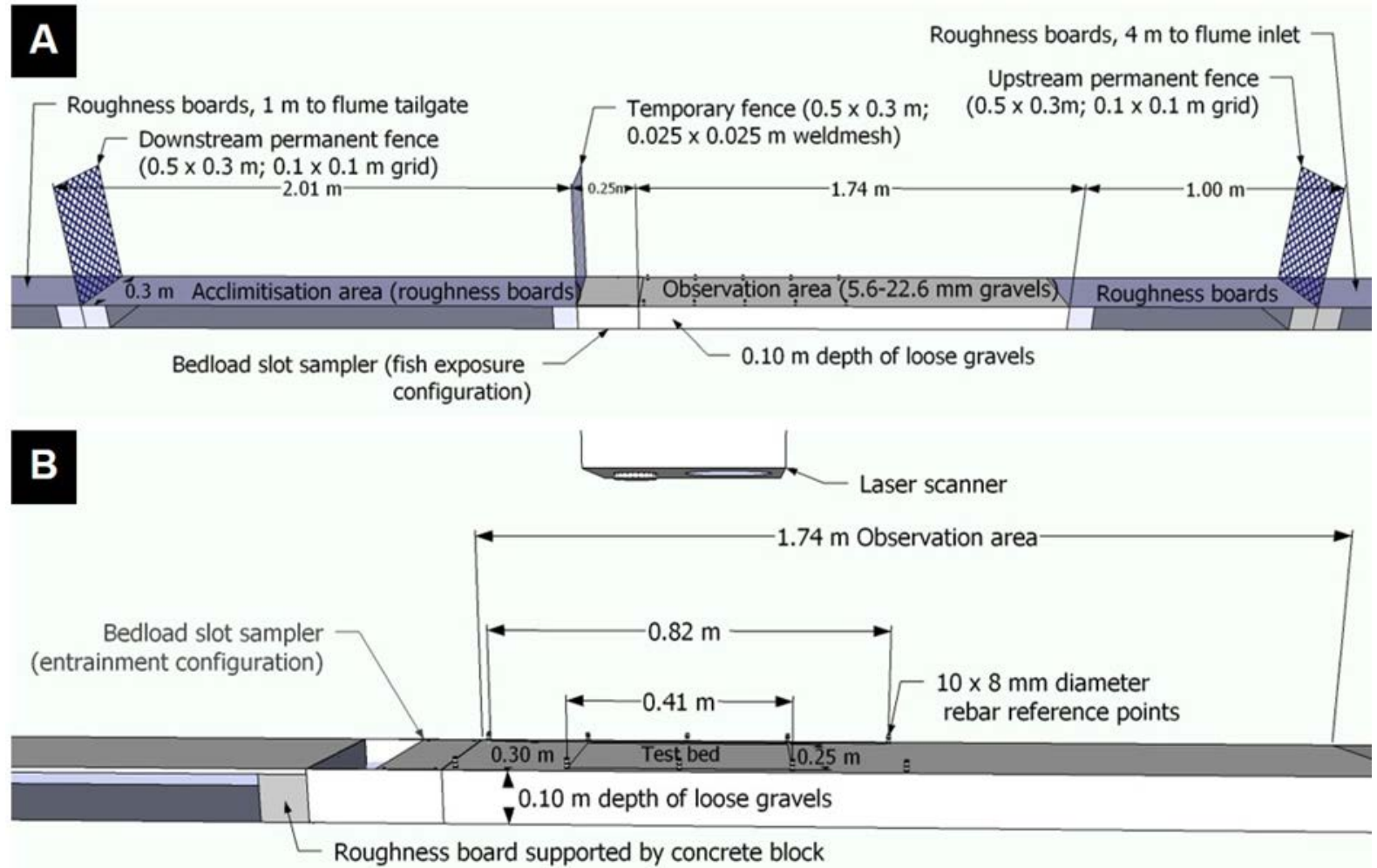

Fig. 1. (A) A three-dimensional (3D) model of the flume setup whilst fish were in the channel during the acclimatization period. Removal of the central, temporary fence allowed fish free access to the 5-m-long experimental enclosure during experiments. (B) A 3D model of the flume setup during phases 1 and 3. Model shows the spatial locations of the bedload slot sampler, laser scanner, and test bed. Note: flow from right to left in all images. 


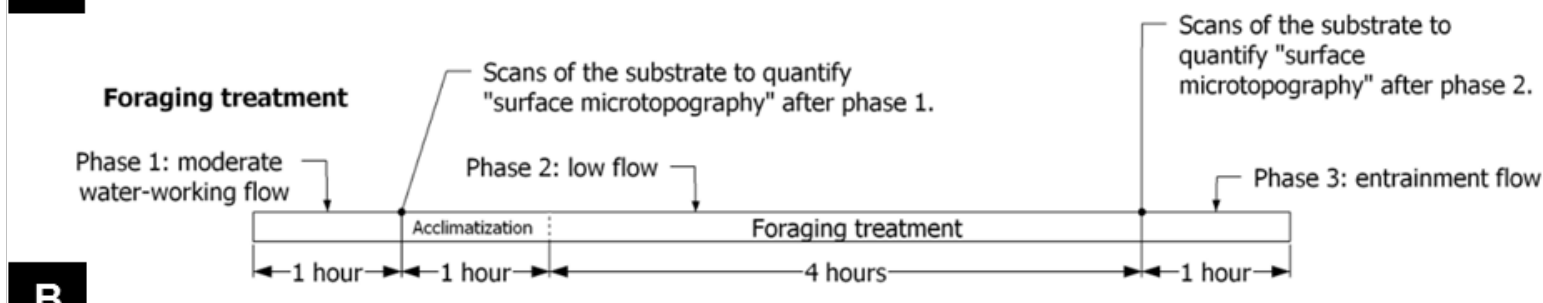

B

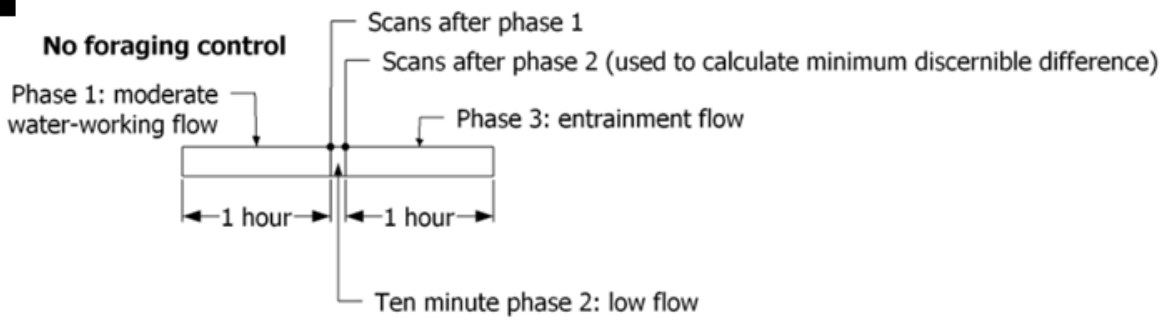

Fig. 2. Schematic diagram presenting the experimental procedure for $(\mathbf{A})$ with Barbel and with Chub foraging treatment; and (B) no foraging control runs. 

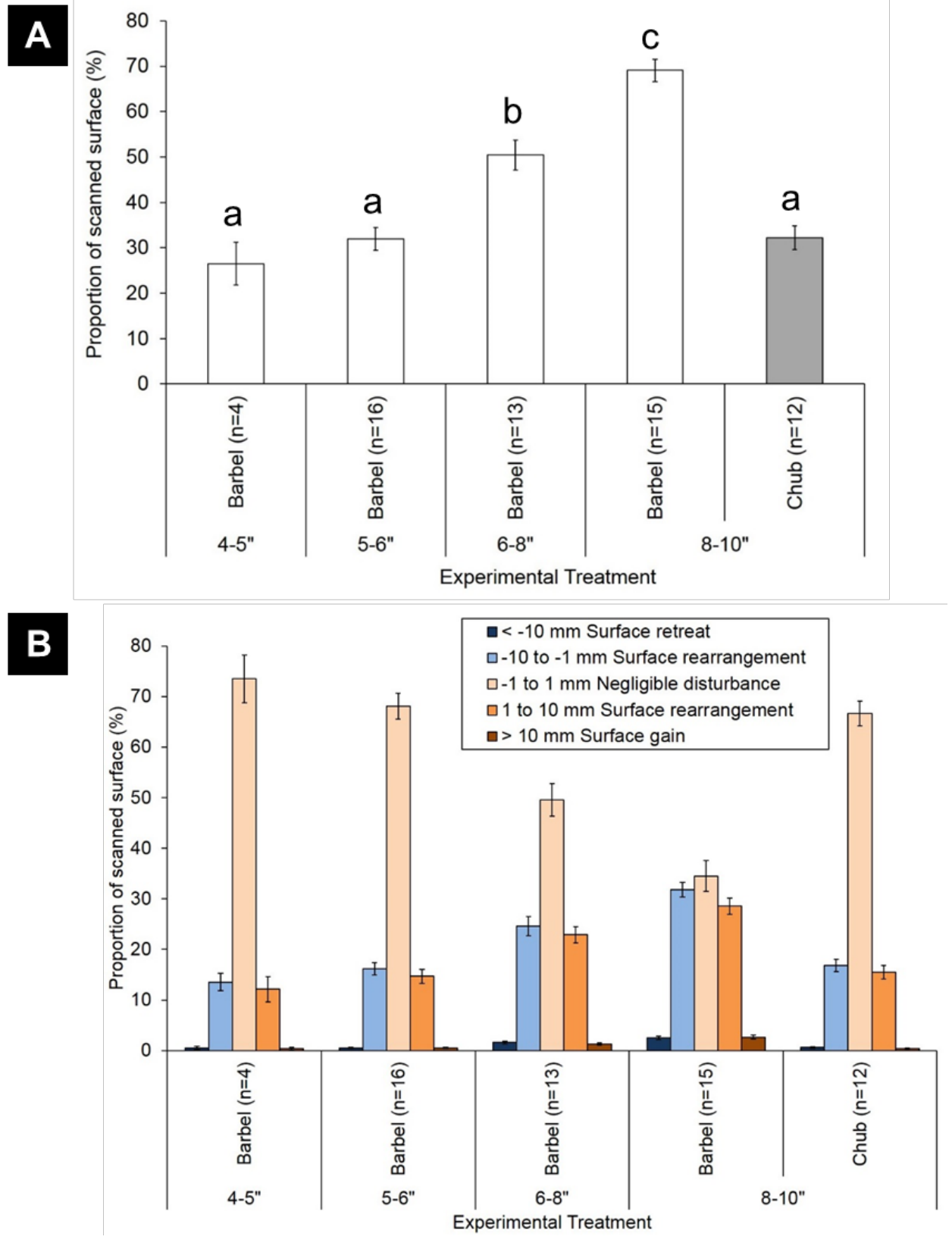

Fig. 3. (A) Total proportion of the river bed disturbed by foraging fish during the four hours of fish activity in a low-velocity flow $\left(0.01 \mathrm{~m} \mathrm{~s}^{-1}\right)$. (B) Mean surface elevation change as a percentage of the DEM surface area (5.6-22.63 $\mathrm{mm}$ gravel surfaces, $0.48 \times 0.28 \mathrm{~m})$ before and after 4 hours of fish activity in a low-velocity flow $(0.01 \mathrm{~m}$ $\left.\mathrm{s}^{-1}\right)$. In each case, values represent treatment means ( \pm SE) and replicate numbers included within $x$-axis labels. In (A), letters above bars indicate homogeneous groups. 


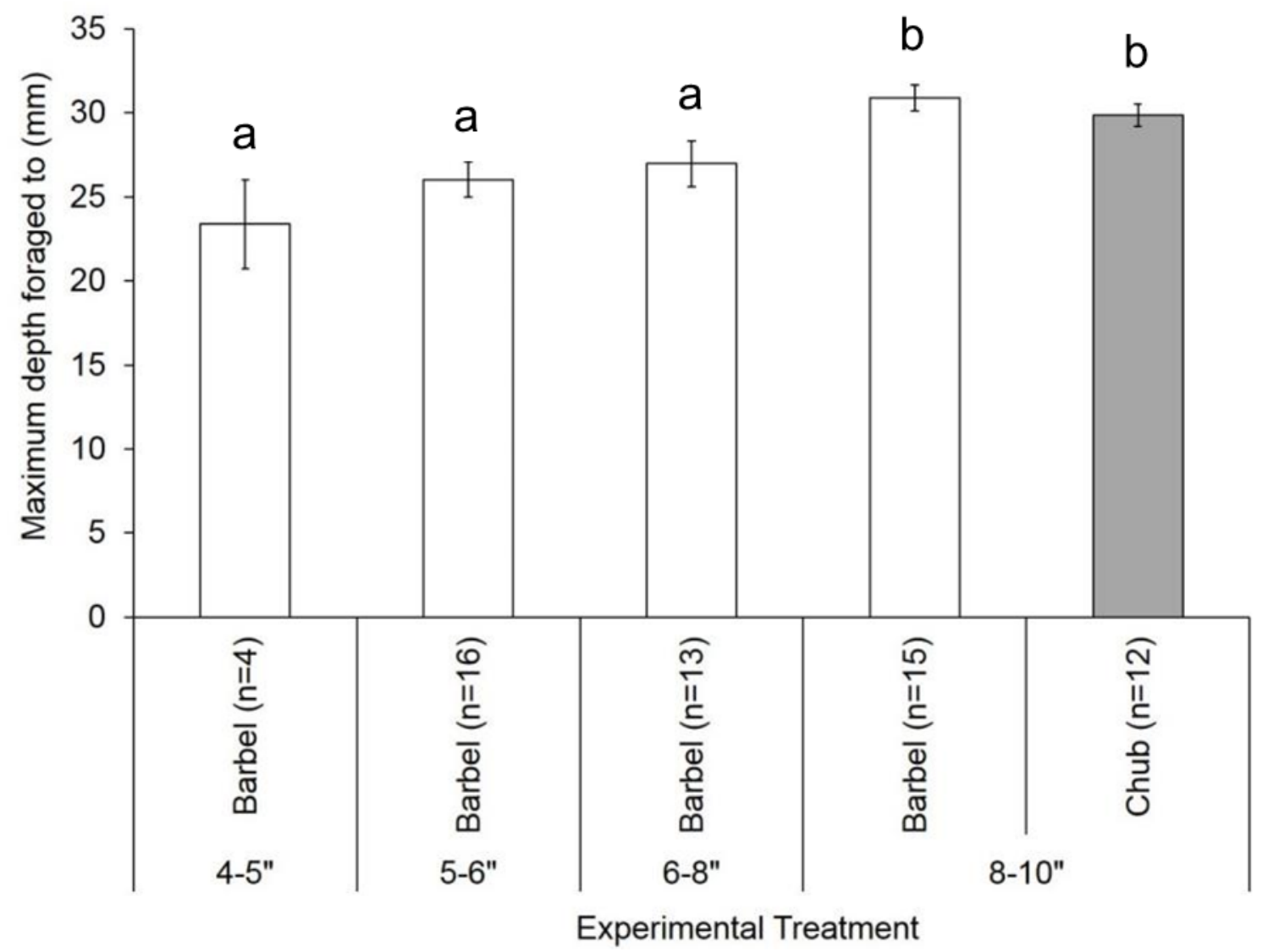

Fig. 4. The maximum depth foraged to by Barbel during the experimental period for each of the four size classes of Barbel and one size class of Chub. Values represent means $( \pm S E)$. Replicate numbers displayed as part of $x$-axis label. Letters above bars indicate homogeneous groups. 

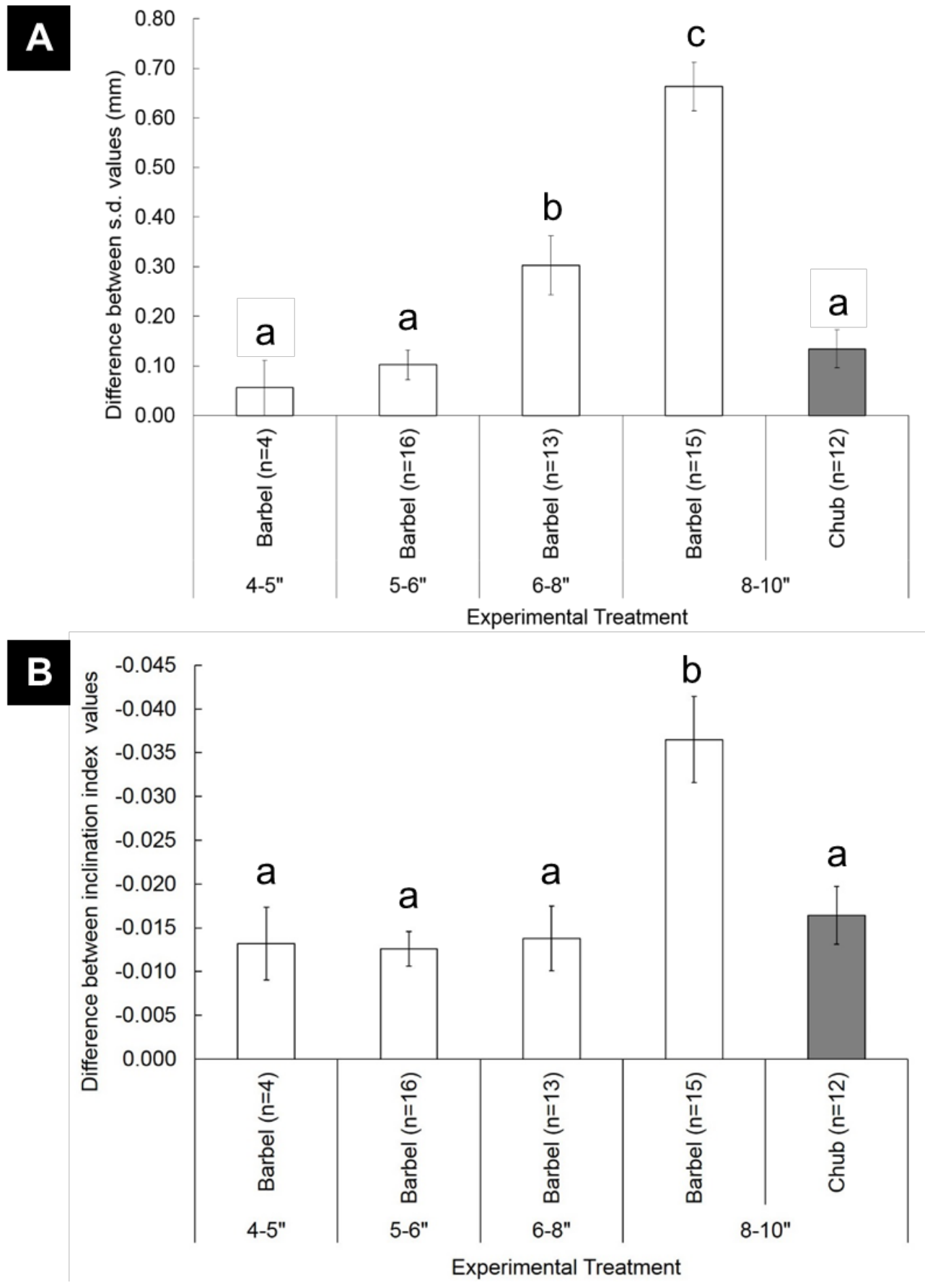

Fig. 5. The mean difference between (A) microtopgraphic roughness values $\left(\Delta \sigma_{z}\right)$ and $(B)$ inclination index values $\left(\Delta I_{l}\right)$, comparing values before and after foraging for each of the four size classes of Barbel and one size class of Chub. Values represent means $( \pm S E)$. Replicate numbers displayed as part of $x$-axis label. Letters above bars indicate homogeneous groups. 


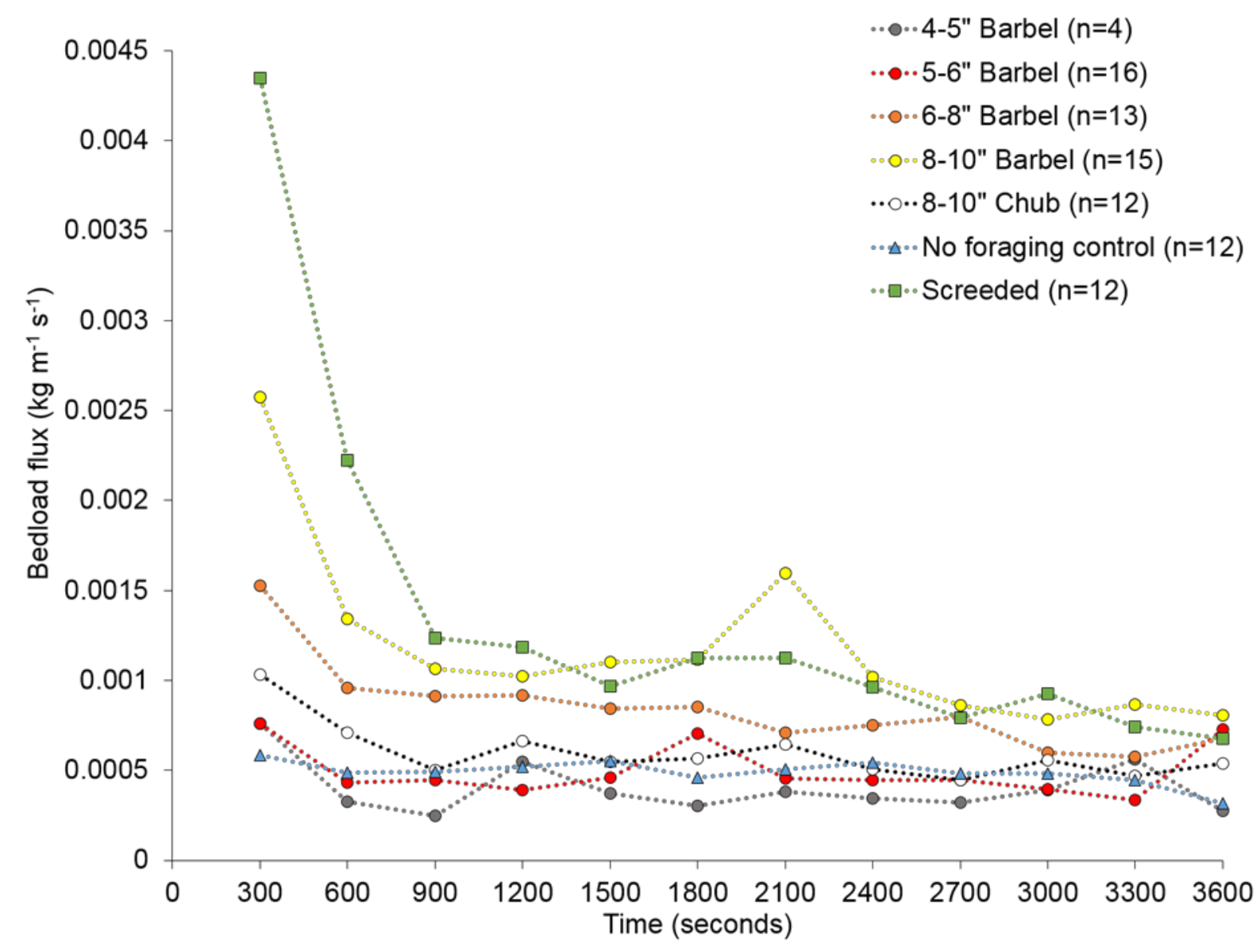

Fig. 6. Mean bedload flux (measured averages for 5-minute periods) during phase 3 (entrainment flow) for foraging treatment, no foraging control, and screeded runs. Replicate numbers included within legend. 


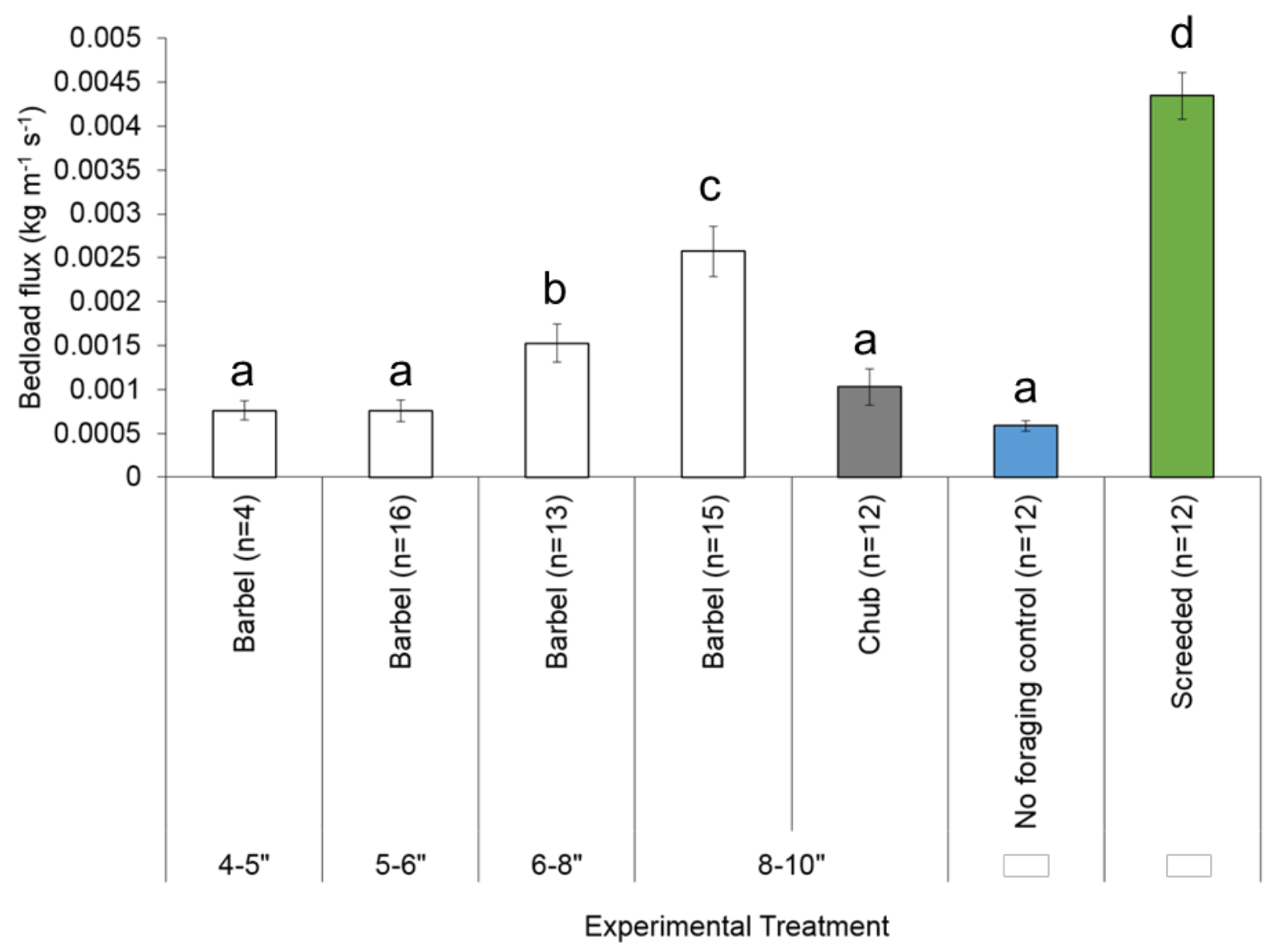

Fig. 7. The impact of foraging fish on the stability of water-worked, gravel-bed textures. Sediment flux after 300 seconds of the steady entrainment flow for screeded, water-worked control, and with-fish treatment runs. Values represent means $( \pm S E)$. Replicate numbers displayed as part of $x$-axis label. Letters above bars indicate homogeneous groups. 


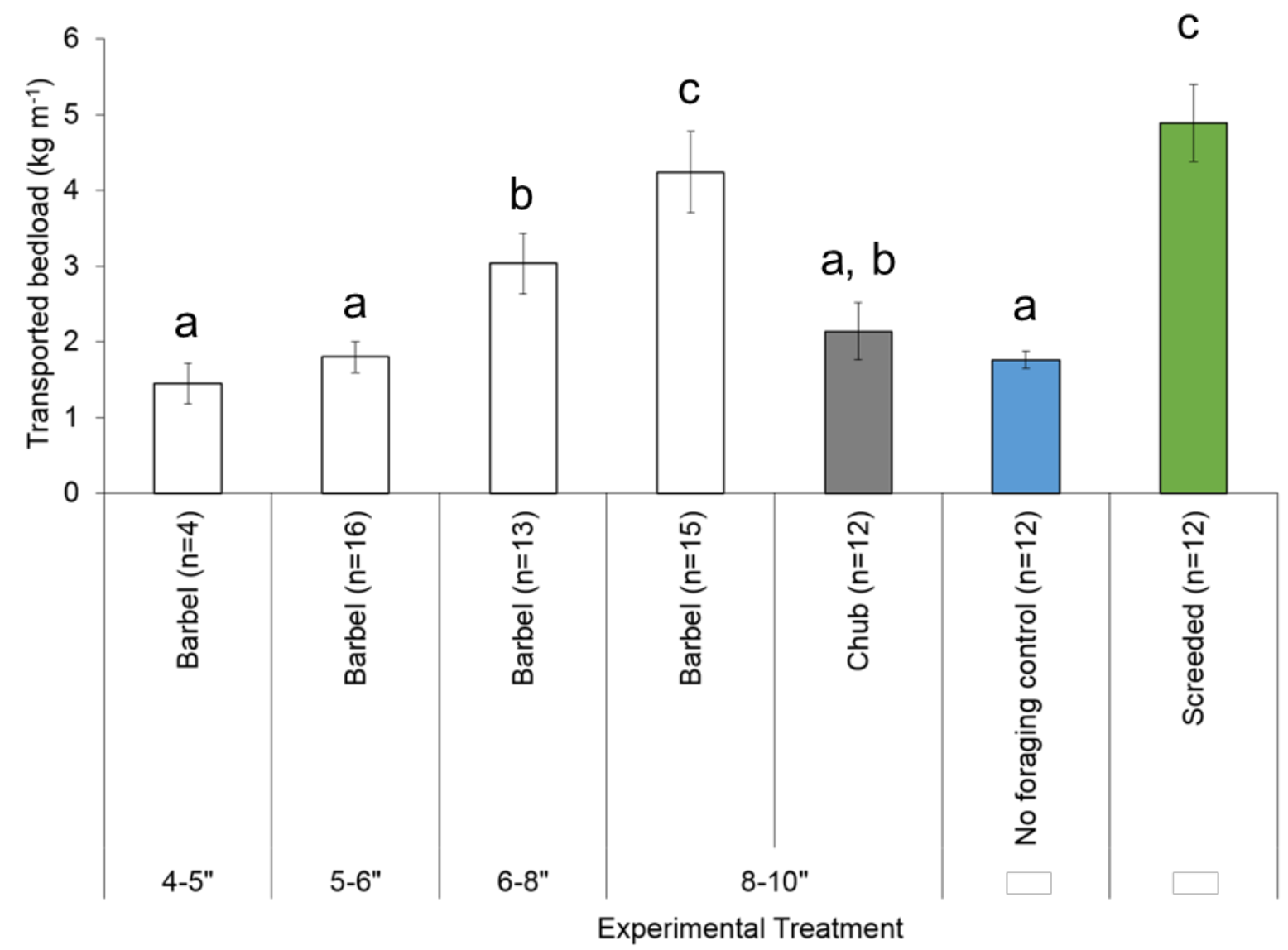

Fig. 8. The impact of foraging fish on the stability of water-worked, gravel-bed textures. Total transported mass after 3600 seconds of the steady entrainment flow for screeded, water-worked control and with-fish treatment runs. Values represent means $( \pm S E)$. Replicate numbers displayed as part of $x$-axis label. Letters above bars indicate homogeneous groups. 

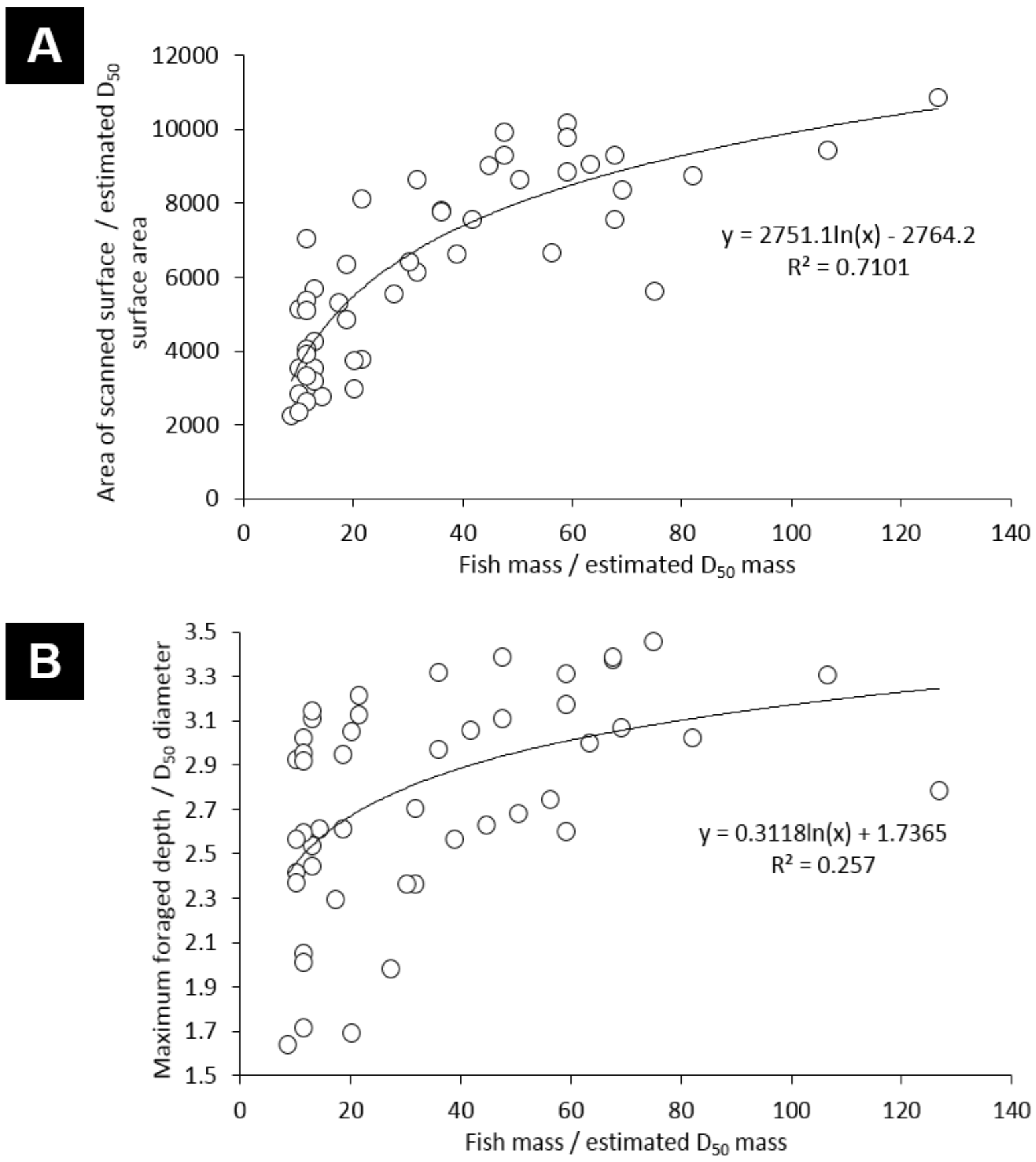

Fig. 9. Allometric relations between (A) total foraged area and Barbel size and (B) maximum foraged depth and Barbel size. Foraged area $\left(\mathrm{m}^{2}\right)$, foraged depth $(\mathrm{m})$, and fish mass $(\mathrm{kg})$ have been nondimensionalised against estimated area $\left(\mathrm{m}^{2}\right)$, diameter $(\mathrm{m})$, and estimated mass $(\mathrm{kg})$ of the $D_{50}$, respectively. In (A), estimated $D_{50}$ surface area pertains to planview surface area, i.e., area of a circle. 
Table 1. Mean total length and mass values $( \pm S D)$ of fish, utilised during the experiment

\begin{tabular}{|c|c|c|c|c|c|}
\hline Species & $\begin{array}{l}\text { Size } \\
\text { (inch) }\end{array}$ & $\begin{array}{c}\text { Age } \\
\text { (years) }\end{array}$ & $\begin{array}{l}\text { Mean total length } \\
\text { (m) }\end{array}$ & $\begin{array}{c}\text { Mean mass } \\
(\mathrm{kg})\end{array}$ & Replicates \\
\hline Barbel & $4-5$ & $2-2.5$ & $0.124 \pm 0.0006$ & $0.014 \pm 0$ & 4 \\
\hline Barbel & $5-6$ & $2.5-3$ & $0.135 \pm 0.002$ & $0.019 \pm 0.001$ & 16 \\
\hline Barbel & $6-8$ & $3-3.5$ & $0.179 \pm 0.004$ & $0.044 \pm 0.004$ & 13 \\
\hline Barbel & $8-10$ & $3.5-4$ & $0.233 \pm 0.008$ & $0.095 \pm 0.008$ & 15 \\
\hline Chub & $8-10$ & $3.5-4$ & $0.233 \pm 0.049$ & $0.13 \pm 0.008$ & 12 \\
\hline
\end{tabular}


Table 2. Flow characteristics during the three phases of each run

\begin{tabular}{|c|c|c|c|}
\hline Flow parameters & $\begin{array}{c}\text { Phase 1: } \\
\text { water working } \\
\text { flow }\end{array}$ & $\begin{array}{c}\text { Phase 2: low } \\
\text { flow } \\
\text { (with or } \\
\text { without } \\
\text { foraging) }\end{array}$ & $\begin{array}{c}\text { Phase 3: entrainment } \\
\text { flow }\end{array}$ \\
\hline Slope; \% & 1.05 & 0 & 1.75 \\
\hline $\begin{array}{l}\text { Average velocity (0.6 } \\
\text { depth); } \mathrm{m} \mathrm{s}^{-1}\end{array}$ & 0.36 & 0.01 & 0.37 \\
\hline $\begin{array}{l}\text { Local bed shear stress; } \\
\mathrm{N} \mathrm{m}^{-2}\end{array}$ & 4.25 & 0.01 & 4.98 \\
\hline Bed shear stress & & & \\
\hline $\begin{array}{l}\text { corrected for sidewall; } \\
\mathrm{N} \mathrm{m}^{-2}\end{array}$ & 3.31 & 0.01 & 4.03 \\
\hline $\begin{array}{l}\text { Shields' dimensionless } \\
\text { shear stress parameter }\end{array}$ & 0.020 & 0.00042 & 0.025 \\
\hline Reynolds number & 21529 & 817 & 20086 \\
\hline
\end{tabular}

Local bed shear stress was corrected for sidewall effects using Williams' (1970) empirical function and the corrected value was used to estimate Shields parameter values. During phase 2, bed slope was set to zero; but pumping water into the top of the flume and allowing it to overfall the tailgate weir generated a water surface slope and desired velocity that was extremely low, but nevertheless measureable. 
Table 3. Microtopographic roughness (SD of surface elevations), inclination index, and $t$-test (paired) statistics for the difference between substrates before and after exposure to Barbel and Chub during phase 2 of fish runs (values represent means $\pm S E)$

Test statistics

Treatment After phase 1 After phase 2 df $t$ value $P$-value

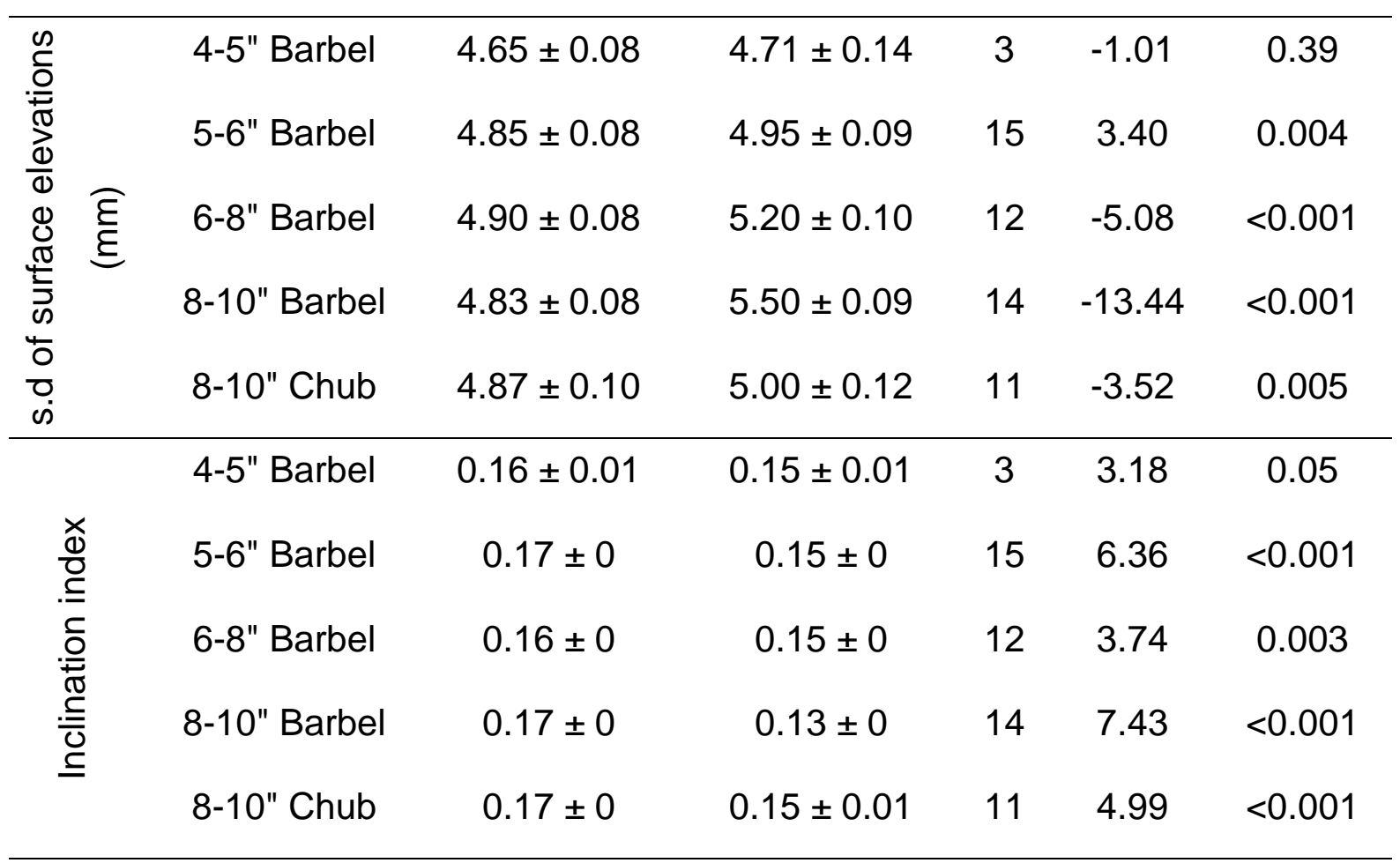

